Research Article

\title{
Structural and Electrical Properties of the YSZ/STO/YSZ Heterostructure
}

\author{
Yue Fan, Wende Liu, Zhenfeng Kang, Tiezhu Ding, Qingrui Bo, \\ Lingling Xiao, Xiaobing Bai, Pingping Zheng, and Qiang Li
}

Inner Mongolia Key Laboratory of Semiconductor Photovoltaic Technology, Inner Mongolia University, Hohhot 010021, China

Correspondence should be addressed to Tiezhu Ding; pytzding@imu.edu.cn

Received 22 April 2014; Revised 8 June 2014; Accepted 9 June 2014; Published 23 June 2014

Academic Editor: Xiaohu Huang

Copyright (C) 2014 Yue Fan et al. This is an open access article distributed under the Creative Commons Attribution License, which permits unrestricted use, distribution, and reproduction in any medium, provided the original work is properly cited.

\begin{abstract}
The heterostructure thin films of yttria-stabilized zirconia (YSZ)/strontium titanate (STO)/YSZ with various thicknesses were deposited on $\mathrm{MgO}$ single crystal substrate by pulsed laser deposition (PLD) method. The structural and electrical properties of the YSZ/STO/YSZ heterostructure were studied through X-ray diffraction (XRD) and electrical conductivity measurements. The in-plane conductivities of the thin films were measured and compared with that of the bulk sample. The highest conductivities were reported for those samples with the thinnest YSZ (220) layers. The observed enhancement in the lateral ionic conductivity was probably caused by the combination of the misfit dislocation density and elastic strain in the interfaces. The enhanced ionic mobility was discussed in terms of the disorder introduced in the oxygen sublattice through the epitaxial strain at the interfaces.
\end{abstract}

\section{Introduction}

The search for new strategies to enhance the oxide ionic conductivity of oxide materials is very active field of research. The portable application of microsolid state fuel cells (m-SOFCs) requires a reduction in the operation temperatures, where the ionic conductivity of the electrolytes, as crucial parts of the solid oxide fuel cells (SOFCs), should be improved at lower temperatures [1]. Yttria-stabilized zirconia (YSZ) is a wellknown oxygen ion conductor, where oxygen vacancies are introduced through the aliovalent substitution of zirconium $(\mathrm{Zr})$ by yttrium $(\mathrm{Y})$. The substitution of $\mathrm{Zr}$ by $\mathrm{Y}^{3+}$ in a $4^{+}$ oxidation state produces an oxygen vacancy for every two $Y$ atoms. The Y substitution stabilizes a cubic fluorite structure, where oxygen occupies the tetrahedral sites of the cubic unit cell. Technologically, YSZ is a very relevant material as an electrolyte in SOFCs. However, it is limited to high temperature applications $\left(>800^{\circ} \mathrm{C}\right)$, where an acceptable performance can be realized. Much interest has been given in acquiring this material as dense thin films to reduce the ohmic resistance of devices and consequently allow lower operating temperatures. The coherent growth of strained interfaces in heterostructures, combined with materials with different degrees of lattice mismatch, has been proposed to possibly promote ion diffusivity [2]. Thus, these heterostructures may have an important role in the optimization of materials for energy generation and storage. This coherent growth of strained heterostructure interfaces is a characteristic of YSZ/strontium titanate (STO) heterostructure, where different structures (fluorite versus perovskite) are combined with a large lattice mismatch of 7\% [3]. The interface between the highly dissimilar structures stabilizes a disordered oxygen sublattice with an increased number of oxygen vacancies, which promotes oxygen diffusion. Decreasing the size of the system to the nanometer length scale leads to a dominant influence of the interfaces on the overall ionic conductivity of the system. Novel phases can be stabilized with enhanced carrier densities and, eventually, mobility. The nanosize effects in conventional ionic conductors are widely accepted in providing novel routes for achieving higher ionic conductivities $[4,5]$. These nanosize effects will be the main focus of this paper, where the ionic conductivity of the YSZ/STO/YSZ electrolyte film enhancement will be described. 


\section{Experimental Procedures}

The pulsed laser deposition (PLD) method has become an increasingly important technique for depositing thin films of various materials. The main advantage of PLD method is its ability to deposit almost any material, while preserving the stoichiometry of multicomponent materials [6]. Furthermore, the PLD technique can operate at a low processing temperature (below $800^{\circ} \mathrm{C}$ ) without high postannealing temperature. This experiment utilized PLD fabricated epitaxial heterostructure films, with blocks made of alternate layers of $8 \mathrm{YSZ}$ ( $8 \mathrm{~mol} \%$ ) and $\mathrm{SrTiO}_{3}$ (99.999\% purity). The laser beam was focused on a high vacuum chamber onto a computer controlled multitarget rotating system. Among the different film deposition techniques, the PLD method is particularly promising because of the ability of this method to reproduce specific target compositions of the film. The films were deposited on $\mathrm{MgO}$ substrates through PLD using a $\mathrm{KrF}$ excimer laser $(\lambda=248 \mathrm{~nm})$ at a frequency of $5 \mathrm{~Hz}$ and an energy density of $5 \mathrm{~J} / \mathrm{cm}^{2}$. During the deposition, each target rotated around the perpendicular axis to the surface. The laser beam was focused on the target rotated at $10 \mathrm{rpm}$ and on the dense targets in a $5 \mathrm{~Pa}$ atmosphere of pure $\mathrm{O}_{2}$. The substrates were positioned parallel to and $5 \mathrm{~cm}$ away from the target. This distance allows sufficient interaction between the plasma plume and the background oxygen gas. The substrate temperature was maintained at $700^{\circ} \mathrm{C}$ during the deposition. To enhance the sticking coefficient and improve the density and crystalline degree of the film, the samples were annealed in oxygen gas at $800^{\circ} \mathrm{C}$ for $1 \mathrm{~h}$ after deposition. By controlling the sputtering time, the YSZ/STO/YSZ trilayers, with different nominal thicknesses of the YSZ interlayer, were deposited through the PLD method on the MgO single crystal substrates.

The YSZ/STO/YSZ trilayers were obtained with various thicknesses of the individual YSZ layers ranging from $62 \mathrm{~nm}$ to $203 \mathrm{~nm}$, whereas the thicknesses of the STO were kept at $62 \mathrm{~nm}$. The physical thicknesses were evaluated using a growth rate of $1 \AA /$ s.

The microstructures, crystallinity, and growth orientation of the YSZ/STO/YSZ thin films were investigated by X-ray diffraction (XRD) using $\mathrm{Cu}-\mathrm{Ka}$ radiation. To analyze the conductance of the films, the in-plane AC impedance was measured between two Ag parallel contacts deposited on the film surface [7]; the measurement was performed at temperatures ranging from $350^{\circ} \mathrm{C}$ to $600^{\circ} \mathrm{C}$ in air with a frequency range from $40 \mathrm{~Hz}$ to $10 \mathrm{MHz}$.

\section{Results and Discussion}

3.1. Microstructure of YSZ/STO/YSZ Epitaxial Heterostructure Films. Figure 1 illustrates the XRD features of the films with various YSZ thicknesses, along with the strong MgO (110) peaks of the substrate. The XRD analyses clearly indicated that these films are composed of individual layers of STO and YSZ.

The XRD pattern exhibited a well-cubic fluorite structure, and the sharp lines of the XRD peaks can be observed, indicating that the heterostructure thin films were formed

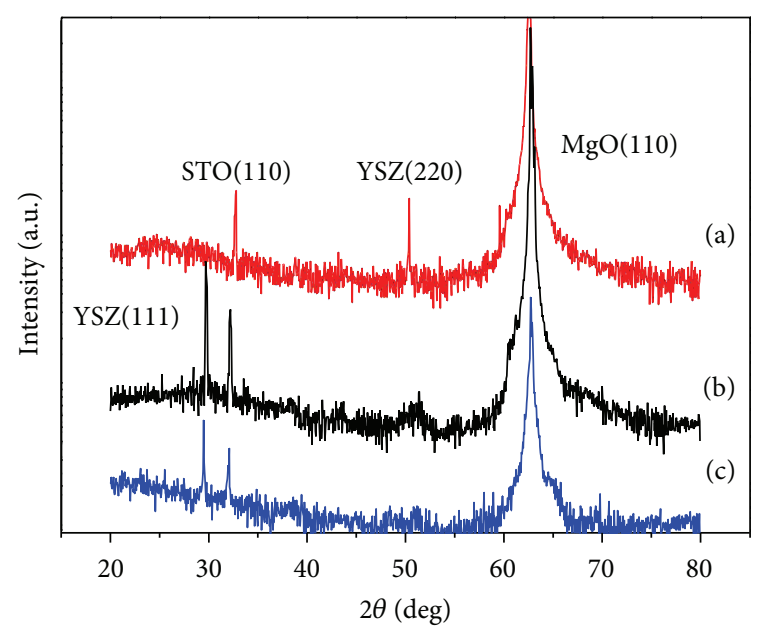

FIGURE 1: XRD patterns of YSZ/STO/YSZ heterostructure electrolyte thin films with different thicknesses, where the thickness of the STO remains at $62 \mathrm{~nm}$, whereas those of the thickness of YSZ are (a) $62 \mathrm{~nm}$, (b) $117 \mathrm{~nm}$, and (c) $203 \mathrm{~nm}$.

after sintering at $800^{\circ} \mathrm{C}$ for $1 \mathrm{~h}$. Figure 1 shows that the (110) diffraction peaks from the $\mathrm{MgO}$ substrate and STO buffer layer were aligned with the reference data, and the intensities of the YSZ/STO/YSZ films also increased when the film thickness ranged from $62 \mathrm{~nm}$ to $203 \mathrm{~nm}$. The preferred orientation of the YSZ film changed from (111) to (220) when the thickness of the YSZ decreased from $203 \mathrm{~nm}$ to $62 \mathrm{~nm}$ (for the constant STO thickness). This change in orientation indicated that the YSZ layers experienced larger lattice strain across the layer to adapt an in-plane orientation with the STO layers and the YSZ was fully strained to the lattice parameters of the STO [4]. This growth mode results in comparatively low interfacial and surface energies of (220) oriented grains and expanded lattice spacing of the layers.

From the surface view, the YSZ/STO/YSZ film appeared to be quite dense and homogeneous without any delamination at the interfaces, and the film adhered well to the $\mathrm{MgO}$ substrate. No cracks or pores are present on the layer after the annealing, which is probably a result of the residual stresses in the annealed thin film. Based on the cross-sectional SEM images, the thickness of each of the STO layers was about $62 \mathrm{~nm}$.

3.2. Electrical Characterization. Electrochemical impedance spectroscopy (EIS) analysis allows separation of the impedance contribution of the electrolyte (at high frequencies) from that of the electrode (at low frequencies). EIS measurements can be performed using a two-electrode configuration that does not require a reference electrode, which would be difficult to place in a thin-film sample [8]. Electrical conductivity measurements for the YSZ/STO/YSZ samples were performed between $350^{\circ} \mathrm{C}$ and $600^{\circ} \mathrm{C}$ at $50^{\circ} \mathrm{C}$ steps. Highresistance substrates need to be used for the electrical measurements of the in-plane conductivity of the thin film. The measured conductance of the $\mathrm{MgO}$ substrate was about three orders lower than that of the YSZ/STO/YSZ film. Hence, 


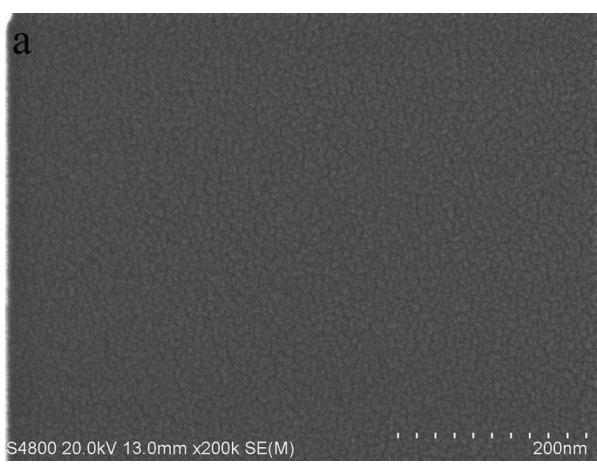

(a)

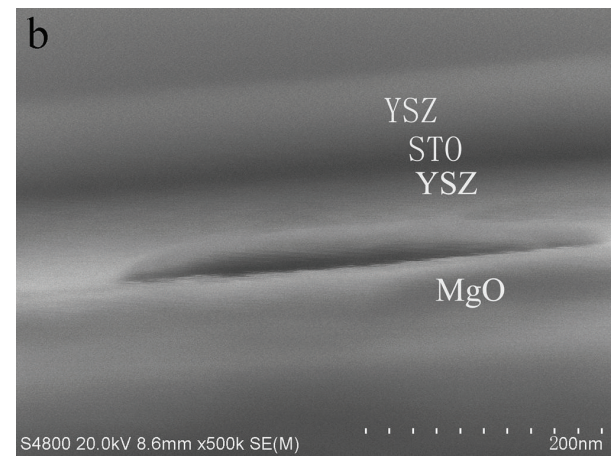

(b)

FIGURE 2: (a) Surface SEM images of the YSZ/STO/YSZ (YSZ = $62 \mathrm{~nm}$ ) film on MgO (110) substrate after sintering at $800^{\circ} \mathrm{C}$ for $1 \mathrm{~h}$. (b) Crosssectional SEM images of the YSZ/STO/YSZ film.

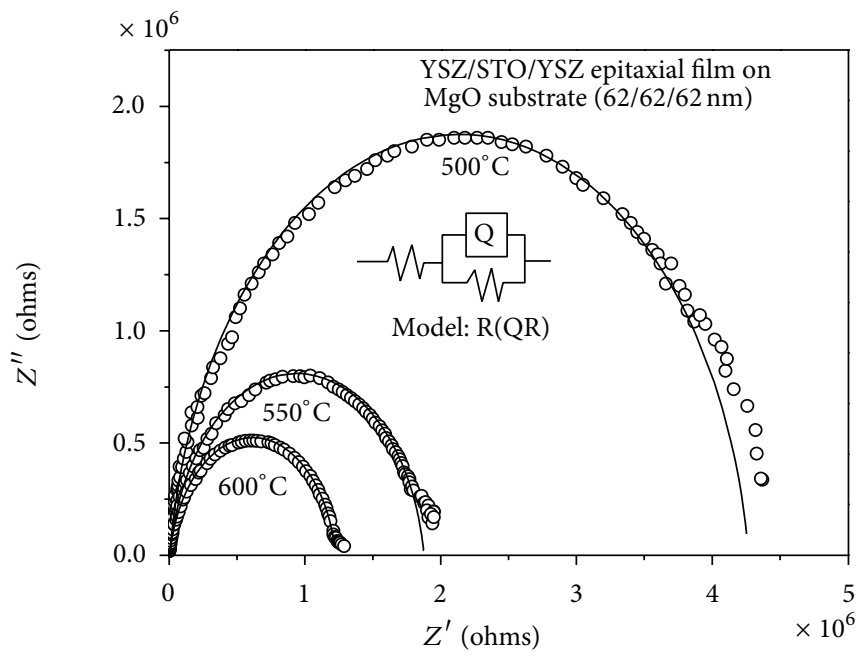

FIGURE 3: Impedance spectra (open symbols) and corresponding fit curves (lines) measured at $500^{\circ} \mathrm{C}, 550^{\circ} \mathrm{C}$, and $600^{\circ} \mathrm{C}$ for the $\mathrm{YSZ} / \mathrm{STO} / \mathrm{YSZ}$ epitaxial films on $\mathrm{MgO}$ substrates in dry air; the inset shows an equivalent circuit.

the substrate resistance was negligible compared with that of the YSZ/STO/YSZ film because of the small geometrical factor.

Figure 3 displays the typical Nyquist plots for the annealed YSZ/STO/YSZ samples at various temperatures under open air and with the corresponding temperature dependent on the total ohmic resistance. Together with the fit curves of the presented equivalent circuit, the patterns consist of only one semicircle attributed to the response of the samples, which are slightly asymmetric in the low frequency range. An equivalent (RQ) R circuit (inset) was used in the fitting procedure to obtain the resistances $\mathrm{R}$, with $\mathrm{Q}$ representing the constant phase element.

The ionic conductivities of the films were analyzed by AC impedance method. Figure 4 illustrates the Arrhenius plots of the electrical conductivities measured in dry air, with a temperature range from $350^{\circ} \mathrm{C}$ to $600^{\circ} \mathrm{C}$, for the YSZ/STO/ YSZ heterostructures with different thicknesses. The electrical conduction of the bulk YSZ is also shown in Figure 4 for comparison. The bulk YSZ sample shows the well-known Arrhenius behavior with activation energy of $1.24 \mathrm{eV}$. All YSZ/ STO/YSZ heterostructures exhibited higher conductivities and smaller activation energies than the bulk YSZ sample. Figure 4 reveals that the reduction in layer thickness causes a decreased active energy; this figure also shows an enhancement in the exhibited ionic conductivity by roughly 3.3 orders of magnitude for the YSZ/STO/YSZ (YSZ = $62 \mathrm{~nm}$ ) trilayer films deposited on the MgO compared with the conductivity values of the bulk YSZ. The ionic conductivity of the YSZ/STO/YSZ $\left(Y S Z=62 \mathrm{~nm}\right.$ ) film was $0.5 \mathrm{~S} / \mathrm{cm}$ at $600^{\circ} \mathrm{C}$, with a conduction activation energy of $0.95 \mathrm{eV}$. The biggest relative conductivity enhancement was found in the lower temperature region. The fact that our structures showed different relative orientations (Figure 2) indicates that the conductivity enhancement may be associated with a particular crystallographic arrangement at the interface.

Two regimes of the conductivity curves were identified with a transition occurring at a temperature of $500^{\circ} \mathrm{C}$. These 


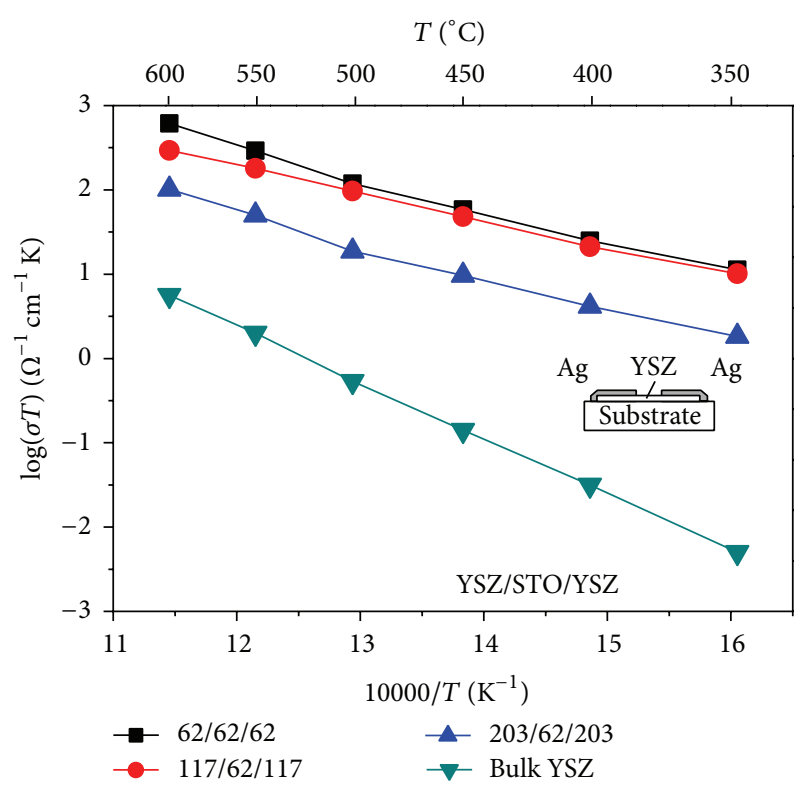

FIGURE 4: Arrhenius plots of the electrical conductivities for the epitaxial YSZ/STO/YSZ thin films with different thicknesses in the temperature range from $350^{\circ} \mathrm{C}$ to $600^{\circ} \mathrm{C}$. The inset shows the electrode configuration for the lateral conductivity measurements.

TABLE 1: Activation energy for the ionic transport measured on different YSZ/STO/YSZ multilayer systems, as shown in Figure 4.

\begin{tabular}{lccc}
\hline $\begin{array}{l}d / \mathrm{nm} \\
\text { Thickness of the } \\
\text { YSZ layer }\end{array}$ & $\begin{array}{c}d / \mathrm{nm} \\
\text { Thickness of the } \\
\text { STO layer }\end{array}$ & $\begin{array}{c}E_{a} / \mathrm{eV} \\
\left(<500^{\circ} \mathrm{C}\right)\end{array}$ & $\begin{array}{c}E_{a} / \mathrm{eV} \\
\left(>500^{\circ} \mathrm{C}\right)\end{array}$ \\
\hline 62 & 62 & 0.64 & 0.95 \\
117 & 62 & 0.71 & 0.98 \\
203 & 62 & 0.76 & 1.12 \\
\hline
\end{tabular}

regimes have very distinct activation energies for oxygen ion migration, which have been found by fitting the linear segments to an Arrhenius expression. These activation energies are shown in Table 1. These observations indicate a superposition of two parallel contributions: one is caused by the bulk lattice, and the other one is attributed to the tensile strain effects $[2,9]$. At lower measuring temperatures $\left(<500^{\circ} \mathrm{C}\right)$, the tensile strain contribution dominates the ionic conductivity. Moreover, this tensile strain contribution increases as the individual layer thickness decreases (as seen in Figure 2), which explains the increase in lateral ionic conductivity as the YSZ layer thickness decreased [10]. At higher temperatures, $\mathrm{O}^{2-}$ ions gain enough thermal energy to overcome the energy barrier $(1.24 \mathrm{eV})$ for ionic conduction through the vacancies in the lattice; hence, a more "bulk-like" conductivity is obtained. Although the conductivity is dominated by bulk lattice diffusion at higher measuring temperatures, a tensile strain contribution is still present [9].

There is much debate surrounding the emergence of colossal ionic conductivity in highly strained films of YSZ/STO heterostructures. Guo, in a comment [11] on the original report [5], concluded that the measured conductivity of the $\mathrm{ZrO}_{2}: \mathrm{Y}_{2} \mathrm{O}_{3} / \mathrm{SrTiO}_{3}$ heterostructure is due to electron holes in $\mathrm{SrTiO}_{3}$ and not oxygen vacancies in YSZ. Cavallaro et al. [12] grew STO/YSZ/STO heterostructures themselves and attributed the enhanced conductivity to an interfacial alloyed oxide resulting from zirconium/strontium intermixing. From the considerations above, we also believe that strain and interfacial effects related to the density of misfit dislocations are at the origin of the enhanced conductivities reported in the present paper.

As discussed earlier, the coherent interfaces formed between the alternating STO and YSZ layers, creating a few dislocations comparable with "single crystals." The contribution of the grain boundary conduction can be disregarded in agreement with the semicircle in Figure 3. By tailoring the thickness of the alternating layers and the lattice mismatch, the interface structure can be manipulated to have very few dislocations; the strain component is confined to the YSZ layers, which significantly improves the ionic conductivity. The strained multilayer film (YSZ $=62 \mathrm{~nm}$ ) displays a greatly enhanced ionic conductivity, with 3.3 orders of magnitude increase, compared with the bulk YSZ at $600^{\circ} \mathrm{C}$

\section{Summary}

This study investigated the structural and electrical properties of the YSZ/STO/YSZ heterostructure and found that preferential growth changes occur from the YSZ (111) to the YSZ (220) when the thickness of the individual layers is further decreased. These changes force YSZ into the lattice parameters of the STO. The strain that is highly confined in the YSZ layers greatly increased the ionic conductivity of the multilayered heterostructure. Atomic reconstruction at the interface was proposed among highly dissimilar structures (such as fluorite and perovskite) to provide both large numbers of carriers and high-mobility plane, yielding to immense values of the ionic conductivity. Thus, the enhanced ion conductance more likely results from the extended defects and lattice strain near the layer interfaces, which may increase the density of the $\mathrm{O}$ vacancies. Defects and strain relaxation may also increase the mobility of the vacancies.

Either new materials with optimized conductivity values have to be sought or new device concepts have to be developed. The interface effects in the epitaxial ionic conducting heterostructures are definitely promising pathways toward novel artificial electrolytes for cooler fuel cells or other electrochemical devices $[2,9]$. However, combined experimental and theoretical efforts will be necessary to understand the ultimate origin of the enhanced conditions of the conductivity interface.

\section{Conflict of Interests}

The authors declare that there is no conflict of interests regarding the publication of this paper.

\section{Acknowledgment}

This work was supported by Natural Science Foundation of China (Approval no. 11264025). 


\section{References}

[1] E. D. Wachsman and K. T. Lee, "Lowering the temperature of solid oxide fuel cells," Science, vol. 334, no. 6058, pp. 935-939, 2011.

[2] A. Rivera-Calzada, M. R. Diaz-Guillen, O. J. Dura et al., "Tailoring interface structure in highly strained YSZ/STO heterostructures," Advanced Materials, vol. 23, no. 44, pp. 5268-5274, 2011.

[3] R. A. de Souza and A. H. H. Ramadan, "Ionic conduction in the $\mathrm{SrTiO}_{3}-\mathrm{YSZ}-\mathrm{SrTiO}_{3}$ heterostructure," Physical Chemistry Chemical Physics, vol. 15, no. 13, pp. 4505-4509, 2013.

[4] J. Garcia-Barriocanal, A. Rivera-Calzada, M. Varela et al., "Tailoring disorder and dimensionality: strategies for improved solid oxide fuel cell electrolytes," ChemPhysChem, vol. 10, no. 7, pp. 1003-1011, 2009.

[5] J. Garcia-Barriocanal, A. Rivera-Calzada, M. Varela et al., "Colossal ionic conductivity at interfaces of epitaxial $\mathrm{ZrO}_{2}$ : $\mathrm{Y}_{2} \mathrm{O}_{3} / \mathrm{SrTiO}_{3}$ heterostructures," Science, vol. 321, no. 5889, pp. 676-680, 2008.

[6] A. Tebano, G. Balestrino, N. G. Boggio, C. Aruta, B. Davidson, and P. G. Medaglia, "High-quality in situ manganite thin films by pulsed laser deposition at low background pressures," European Physical Journal B, vol. 51, no. 3, pp. 337-340, 2006.

[7] O. H. Kwon and G. M. Choi, "Electrical conductivity of thick film YSZ," Solid State Ionics, vol. 177, no. 35-36, pp. 3057-3062, 2006.

[8] G. Hsieh, S. J. Ford, T. O. Mason, and L. R. Pederson, "Expermental limitations in impedance spectroscopy-part I. Simulation of reference electrode artifacts in three-point measurements," Solid State Ionics, vol. 91, no. 3-4, pp. 191-201, 1996.

[9] M. Sillassen, P. Eklund, N. Pryds, E. Johnson, U. Helmersson, and J. Bøttiger, "Low-temperature superionic conductivity in strained yttria-stabilized zirconia," Advanced Functional Materials, vol. 20, no. 13, pp. 2071-2076, 2010.

[10] I. Kosacki, C. M. Rouleau, P. F. Becher, J. Bentley, and D. H. Lowndes, "Nanoscale effects on the ionic conductivity in highly textured YSZ thin films," Solid State Ionics, vol. 176, no. 13-14, pp. 1319-1326, 2005.

[11] X. Guo, "Comment on "colossal ionic conductivity at interfaces of epitaxial $\mathrm{ZrO}_{2}: \mathrm{Y}_{2} \mathrm{O}_{3} / \mathrm{SrTiO}_{3}$ heterostructures"' Science, vol. 324, no. 5926, p. 465, 2009.

[12] A. Cavallaro, M. Burriel, J. Roqueta et al., "Electronic nature of the enhanced conductivity in YSZ-STO multilayers deposited by PLD," Solid State Ionics, vol. 181, no. 13-14, pp. 592-601, 2010. 

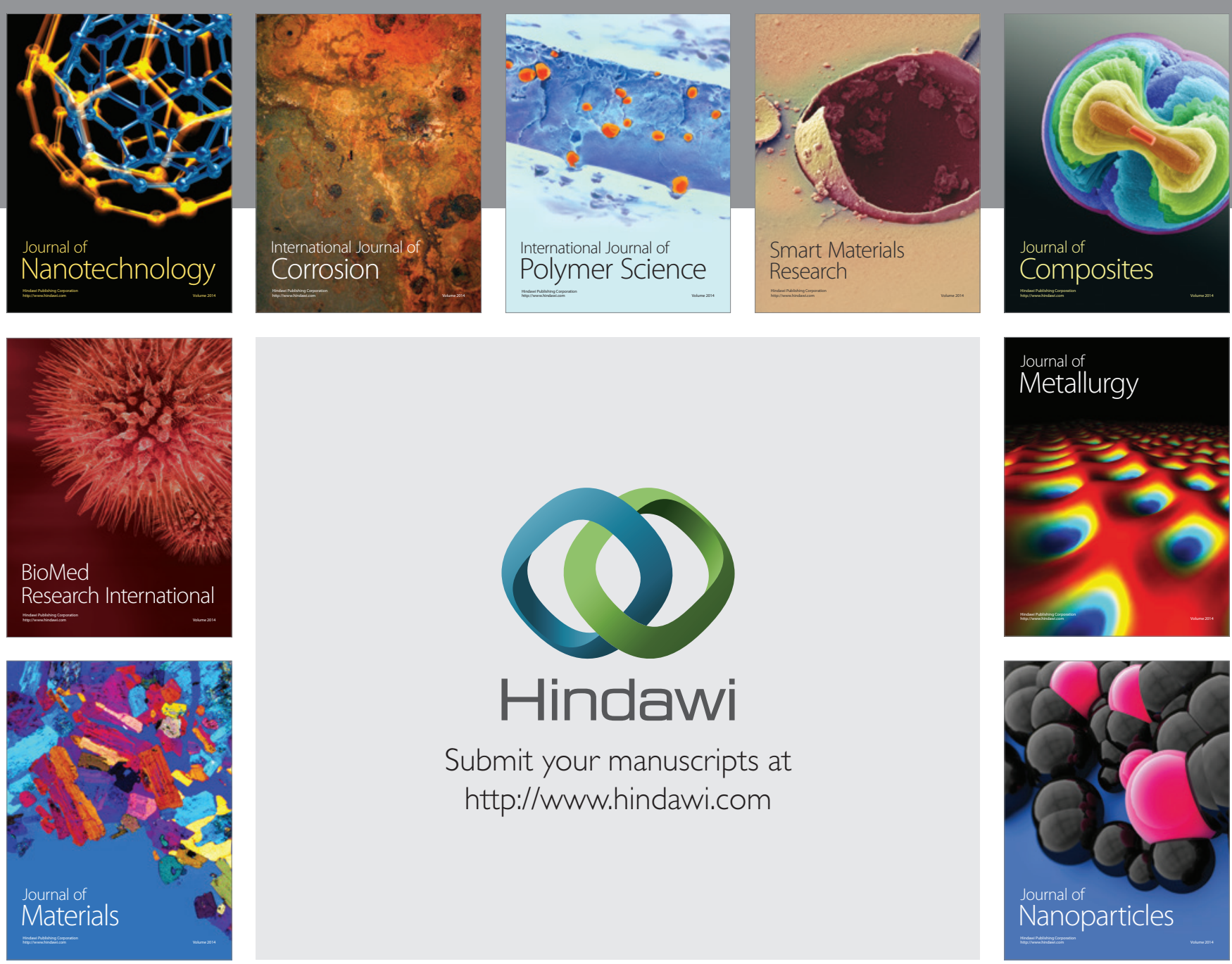

Submit your manuscripts at http://www.hindawi.com
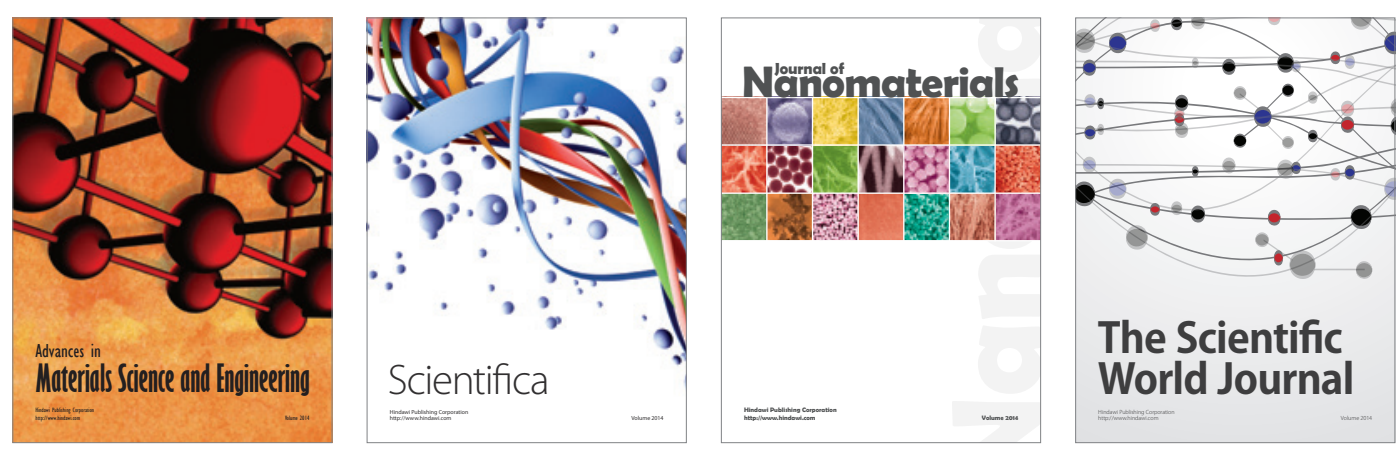

\section{The Scientific World Journal}
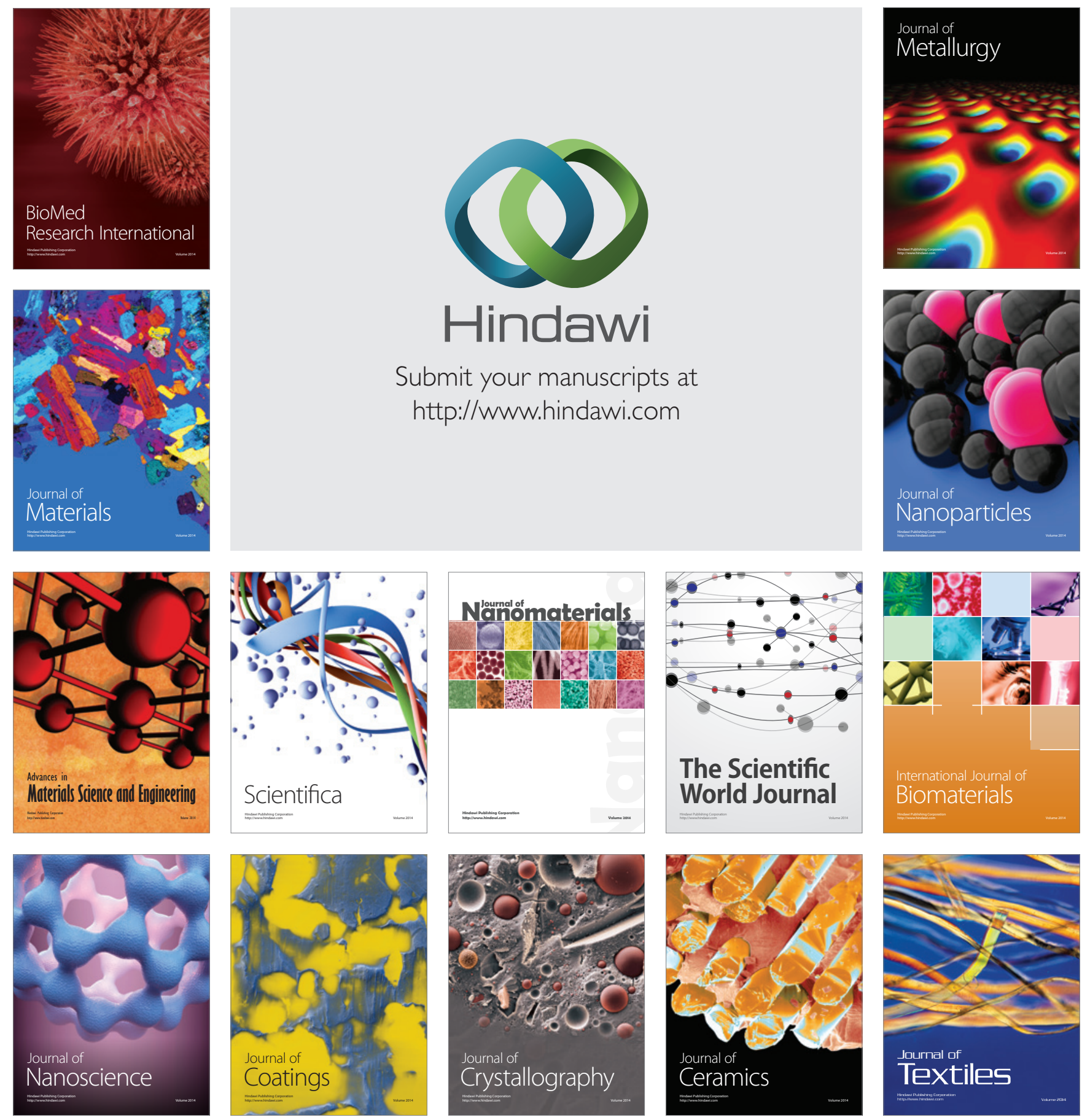